\title{
SURDEZ NA PERSPECTIVA DA EDUCAÇÃO INCLUSIVA
}

\section{Deafness in the perspective of inclusive education}

\author{
Raylene de Oliveira Ribeiro - Faculdade São Francisco de Barreiras /Brasil \\ Maria da Conceição da Cunha Louseiro - Faculdade São Francisco de Barreiras /Brasil
}

RESUMO: A educação especial na perspectiva da inclusão escolar tem evoluído com o passar dos anos, especificamente quando se considera o histórico da exclusão e até mesmo abandono de pessoas surdas. Nessa temática, esse artigo discute sobre o surdo no contexto de educação escolar. Pesquisas realizadas no país apontam que existe um maior índice de pessoas com deficiência na região do Nordeste e a menor no Sudeste, os estados do Rio Grande do Norte 17,6\%, da Paraíba $18,0 \%$ e do Piauí $17,6 \%$ são os que proporcionalmente apresentam o maior número e as menores proporções foram encontradas em São Paulo 11,3\%, no Paraná 13,0\%, e no Distrito Federal 13,4\%. Com isso, conclui-se que é de suma importância a inclusão de pessoas com deficiência nas escolas, sendo importantes as adaptações para que elas sejam incluídas em contextos de educação.

Palavras - Chave: Deficiência auditiva. Exclusão social, Linguagem.

ABSTRACT: Special education from the perspective of school inclusion has evolved over the years, specifically when considering the history of exclusion and even abandonment of deaf people. In this theme, this article discusses the deaf in the context of school education. Surveys conducted in the country indicate that there is a higher rate of people with disabilities in the Northeast and the lowest in the Southeast, the states of Rio Grande do Norte 17.6\%, Paraíba $18.0 \%$ and Piauí $17.6 \%$ are Those that proportionally present the largest number and the smallest proportions were found in São Paulo $11.3 \%$, Paraná $13.0 \%$, and Distrito Federal 13.4\%. Thus, it is concluded that the inclusion of people with disabilities in schools is of paramount importance, and adaptations to include them in educational contexts are important.

Key words: Hearingimpairment, Social exclusion, Language.

\section{INTRODUÇÃO}

De acordo Moura (2017), “os educandos com deficiência auditiva precisam de escolas com recursos, materiais didáticos adequados, professores, gestão escolar, discentes e funcionários habilitados para atender NEE nas escolas e seu currículo adaptado para tais alunos".

A política educacional brasileira prevê que haja, nas escolas regulares ou instituições especializadas, um Atendimento Educacional Especializado (AEE), que seja um suporte para que a educação inclusiva ocorra em nosso país. Um dos fatores de

Educação, Psicologia e Interfaces, Volume 4, Número 1, p.106-113, Janeiro/Março, 2020.

ISSN: 2594-5343. DOI: https://doi.org/10.37444/issn-2594-5343.v4i1.203 
relevância para o alcance deste objetivo é o um trabalho colaborativo entre professores do AEE e professores da sala regular.

A Lei N 9.394 /96 que estabelece as Diretrizes e Bases da Educação Nacional aborda em seu art. 59 em seus incisos I, II, III, IV e V as seguintes necessidades de educandos com deficiências:

\begin{abstract}
Art. 59. Os sistemas de ensino assegurarão aos educandos com necessidades especiais: I - currículos, métodos, técnicas, recursos educativos e organização específica, para atender às suas necessidades; II - terminalidade específica para aqueles que não puderem atingir o nível exigido para a conclusão do ensino fundamental, em virtude de suas deficiências, e aceleração para concluir em menor tempo o programa escolar para os superdotados; III - professores com especialização adequada em nível médio ou superior, para atendimento especializado, bem como professores do ensino regular capacitados para a integração desses educandos nas classes comuns; IV - educação especial para o trabalho, visando a sua efetiva integração na vida em sociedade, inclusive condições adequadas para os que não revelarem capacidade de inserção no trabalho competitivo, mediante articulação com os órgãos oficiais afins, bem como para aqueles que apresentam uma habilidade superior nas áreas artística, intelectual ou psicomotora; $\mathrm{V}$ - acesso igualitário aos benefícios dos programas sociais suplementares disponíveis para o respectivo nível do ensino regular.
\end{abstract}

Nos dias de hoje os surdos ainda são vistos erroneamente e por isso, são caracterizados como: problema, deficientes, anormais, seres patológicos ou qualquer outra denominação de cunho pejorativo. A história dos surdos registra os acontecimentos, como grupo que possui uma língua, identidade e cultura.

Neste sentido, havendo a ausência da educação bilíngue, de interpretes no ambiente escolar torna-se dificultosa a troca de conhecimento entre aluno e professor, e a linguagem por meio de libras não é trabalhada como predominante, mas como uma segunda língua destinada aos surdos. Dessa maneira o papel do professor de AEE é sempre solicitado para possibilitar a comunicação com os servidores da escola, e os indivíduos que sabem o básico (PASSOS; SANTOS; CAMPELO, 2018).

Diante disto, o português como segunda língua $\left(\mathrm{PL}_{2}\right)$ tem se estabelecido atualmente de forma significativa na educação de surdos, no qual a mesma tem como finalidade atenderas necessidades destas pessoas quando estes se tornarem profissionais no mercado de trabalho. "O ensino de $\mathrm{PL}_{2}$ objetiva ainda contribuir para que o estudante

Educação, Psicologia e Interfaces, Volume 4, Número 1, p. 106-113, Janeiro/Março, 2020.

ISSN: 2594-5343. DOI: https://doi.org/10.37444/issn-2594-5343.v4i1.203 
surdo possa desenvolver capacidades para agir socialmente em situações acadêmicas e/ ou profissionais específicas" (SILVA, 2016).

A educação voltada para pessoas surdas vem passando por um processo de crescimento, tendo em vista a necessidade de inserção do ensino dessa linguagem nas escolas, como um método de ensino regular nestas. Onde com isso, propicia-se a formação de identidade, cultura e história, podendo dessa maneira disseminar o seu reconhecimento, sendo possível determinar por meio de pesquisas como se deu o surgimento dos primeiros surdos, além da possibilidade de verificar o seu histórico ao longo dos anos (DIMBARRE; HURKO; GLAP, 2017).

É necessária uma integração entre as diversas políticas do Estado, nas mais diversas áreas, em especifico a educação, para que, de fato, haja uma assistência global a essas pessoas com necessidades especificas inseridas no âmbito educacional, com o intuito de melhorar e estimular os profissionais a refletir sobre a inserção do aluno com necessidades especificas (surdez) na educação chamada inclusiva, assim como alguns fundamentos das políticas públicas para inclusão de surdos na escola.

\section{CONHECENDO A SURDEZ}

O som é um fenômeno resultante da movimentação das partículas do ar. Qualquer evento capaz de causar ondas de pressão no ar é considerado uma fonte sonora. A fala, por exemplo, é o resultado do movimento dos órgãos fonoarticulatórios, que por sua vez provoca movimentação das partículas de ar, produzindo então o som.

Perceber, reconhecer, interpretar e, finalmente, compreender os diferentes sons do ambiente só é possível graças à existência de três estruturas que funcionam de forma ajustada e harmoniosa, constituindo o sistema auditivo humano. O ouvido humano é composto por três partes: uma externa, as outras duas internas localizadas dentro da caixa craniana (NUVOLARI, 2015).

Existem muitos fatores que podem causar perda da audição as quais podem ser decorrentes de diferentes causas como, por exemplo, genéticas, infecciosas, mecânicas, tóxicas, desnutrição e algumas doenças, onde tais fatores podem ainda ocorrer no período do pré-natal perinatal ou pós natal (TIENSOLI et al. 2007).

É considerado como indivíduo com problemas auditivo, quando apresenta qualquer distúrbio ou alteração no processamento normal da audição, seja qual for o grau

Educação, Psicologia e Interfaces, Volume 4, Número 1, p.106-113, Janeiro/Março, 2020.

ISSN: 2594-5343. DOI: https://doi.org/10.37444/issn-2594-5343.v4i1.203 
de severidade, e/ou tipo, sendo assim determinando para o indivíduo uma diminuição da sua capacidade de ouvir e perceber sons (BRASIL, 2006).

É interessante ainda o conhecimento por parte de todos e, principalmente, dos profissionais que trabalham diretamente com alunos surdos, sobre as características da surdez, isso contrinuirá com o melhor desenvolvimento do trabalho pedagógico, com um olhar de compreensão a respeito desse fenômeno, resultando assim no melhor desenvolvimento em atender as necessidades especiais constatadas (BRASIL, 2006).

A medicina tem avançado muito nesse campo e, em casos especiais, se estiver de acordo com a vontade do surdo, há a possibilidade de se fazer a cirurgia coclear, um dispositivo eletrônico tecnológico, o qual tem como objetivo estimular as fibras do corpo responsáveis por reproduzir e transmitir os sons, no entanto muitos se negam a fazer tal uso, pelo fato de se negarem a tal identidade (NASCIMENTO, 2017).

De forma geral, o paciente adulto apresenta-se com queixa própria de dificuldade comunicativa, principalmente para reconhecer os sons da fala, que piora em ambientes ruidosos. É muito frequente a chegada ao consultório de indivíduos cuja queixa não é pessoal, mas dos familiares e amigos que relatam a incompatibilidade entre intensidade sonora de conforto entre eles e o paciente. Nas crianças, os testes objetivos poderão trazer algumas informações sobre integridade de cada uma das estações que formam o sistema auditivo como um todo, mas o entendimento mais preciso da função auditiva poderá ser de difícil obtenção e depender de muitos meses de experimentação, observação e avaliação.

A proporção de pessoas com algum tipo de deficiência é diferente em cada região. A maior proporção encontra- se na região Nordeste 16,8\%, a menor na região Sudeste 13,1\%. Os estados do Rio Grande do Norte 17,6\%, da Paraíba 18,0\% e do Piauí 17,6\% são os que proporcionalmente apresentam o maior número de pessoas com deficiências. As menores proporções foram encontradas em São Paulo 11,3\%, no Paraná 13,0\%, e no Distrito Federal 13,4\% (COSTA LEVY, 2015).

O uso de aparelhos representa para muitos, principalmente aos surdos como sendo algo negativo, visto que isso pode prejudicar a audição e implante coclear, defendendo ainda que a surdez não é uma deficiência e sim um diferença, sendo necessário o uso de recursos os quais venham igualá-los as demais pessoas na sociedade, sem que cause 
desconforto, aproximando-as ainda ao ambiente escolar e da sociedade (NÓBREGA et al. 2012).

\section{O SURDO NA EDUCAÇÃO}

A educação inclusiva é considerada um movimento que envolve vários aspectos sociais, culturais, e éticos, possibilitando assim que os profissionais tenham adaptações neste processo, onde tenham um conhecimento e reflexão da pluralidade das pessoas com necessidades educacionais especiais (CARVALHO, 2013). Para Lima e Carneiro (2016), ressalta que a educação inclusiva tem como objetivo garantir os alunos com ou sem necessidades tenham o mesmo direito como cidadão de participarem de qualquer que seja as atividades planejadas na escola, visto que os alunos com necessidades especificas precisam de adaptações nas atividades para melhor participação de acordo com o grau de habilidade mesmo diante dos desafios.

Excetuando-se as modalidades tradicionais de educação de surdos, que trabalham através desses métodos, que buscam uma forma mediadora demonstrando a importância da diferença cultura existente no surdo fundamental a educação de surdos nesta teorização contemporânea sobre a identidade, parece ser o caminho entramos pela defesa cultural da educação da diferença como mediação intelectual, esta modalidade oferece uma filosofia invariável hoje (PERLIN; STROBEL, 2006).

No âmbito escolar o Atendimento Educacional Especializado (AEE) é considerado como uma rede de serviços voltados ao público da educação especial, ou seja, aos alunos com necessidades especificas, com objetivo de ajuda de caráter complementar e/ou suplementar ao ensino regular do qual está matriculado (BRASIL, 2008).

O Conselho Nacional de Educação afirma ter o compromisso de ofertar o atendimento aos alunos publico alvo da Educação Inclusiva na Resolução no 04 de 2009 no parágrafo que diz que:

[...] os sistemas de ensino devem matricular os alunos com deficiência, transtornos globais do desenvolvimento e altas habilidades/superdotação nas classes comuns do ensino regular e no Atendimento Educacional Especializado (AEE), ofertado em salas de recursos multifuncionais ou em centros de Atendimento Educacional Especializado da rede pública ou de instituições comunitárias, confessionais ou filantrópicas sem fins lucrativos (BRASIL, 2009, p. $1)$. 
As atividades pedagógicas devem ser planejadas com o intuito de inserir os alunos com necessidades especificas no ambiente da sala de aula que deve seguir como orientações as atribuições descritas no Artigo $13^{\circ}$ da Resolução n 4 , de outubro de 2009 :

I - identificar, elaborar, produzir e organizar serviços, recursos pedagógicos de acessibilidade e estratégias considerando as necessidades específicas dos alunos público-alvo da Educação Especial; II - elaborar e executar plano de Atendimento Educacional Especializado, avaliando a funcionalidade e a aplicabilidade dos recursos pedagógicos e de acessibilidade; III - organizar o tipo e o número de atendimentos aos alunos na sala de recursos multifuncionais; IV - acompanhar a funcionalidade e a aplicabilidade dos recursos pedagógicos e de acessibilidade na sala de aula comum do ensino regular, bem como em outros ambientes da escola; V - estabelecer parcerias com as áreas intersetoriais na elaboração de estratégias e na disponibilização de recursos de acessibilidade; VI - orientar professores e famílias sobre os recursos pedagógicos e de acessibilidade utilizados pelo aluno; VII - ensinar e usar a tecnologia assistiva de forma a ampliar habilidades funcionais dos alunos, promovendo autonomia e participação; VIII - estabelecer articulação com os professores da sala de aula comum, visando à disponibilização dos serviços, dos recursos pedagógicos e de acessibilidade e das estratégias que promovem a participação dos alunos nas atividades escolares (BRASIL, 2009).

\section{CONSIDERAÇÕES FINAIS}

Como foi possível observar no trabalho apesar das dificuldades enfrentadas ao longo dos anos, as pessoas com necessidades especiais vem cada vez mais conquistando seus direitos de igualdade, no que diz respeito à educação de qualidade e de inclusão social. Desta forma garantindo a educação de pessoas com surdez ou portadora de algum outro tipo de necessidade.

Com isso é de suma importância que os profissionais da área da educação sejam cada vez mais capacitados para atuarem com pessoas deficientes, tendo em vista que por se tratarem de pessoas com necessidades especiais as mesmas requerem uma maior atenção de forma que os mesmos não venham a se sentir excluídos.

Desta forma conclui-se que é de suma importância a inclusão de pessoas com deficiência nas escolas, e principalmente da estrutura adequada para as mesmas e ainda, que as políticas educacionais sejam de fato seguidas de forma a garantir a igualdade e direito de todas as pessoas com necessidades especiais.

Educação, Psicologia e Interfaces, Volume 4, Número 1, p. 106-113, Janeiro/Março, 2020.

ISSN: 2594-5343. DOI: https://doi.org/10.37444/issn-2594-5343.v4i1.203 


\section{REFERÊNCIAS BIBLIOGRÁFICAS}

BRASIL. Conselho Nacional de Educação. Resolução CNE/CEB n 4/2009, de 2 outubro de 2009. Institui Diretrizes Operacionais para o Atendimento Educacional Especializado na Educação Básica, modalidade Educação Especial. Diário Oficial da União, Brasília, DF, 5 out. 2009a. Seção 1. p. 17.

BRASIL. Lei no 9.394. Diretrizes e Bases para a Educação Nacional. Brasília: Ministério da Educação e Cultura, 1996.

BRASIL. Ministério da Educação. Saberes e práticas da inclusão: desenvolvendo competências para o atendimento às necessidades educacionais especiais de alunos surdos. [2. ed.]/ coordenação geral SEESP/MEC. - Brasília: MEC, Secretaria de Educação Especial, 2006.

BRASIL. Política Nacional de Educação Especial na Perspectiva da Educação Inclusiva. Brasília: MEC/SEESP, 2008.

CARVALHO, R.E. Educação inclusiva: com os pingos nos “is". 9a. Edição - Porto Alegre: Mediação, 2013. 175p.

COSTA LEVY, C. C. A. Manual de audiologia pediátrica. Editora Manole, 2015.

CRUZ, C. R. Consciência fonológica da língua de sinais: implicações na linguagem e na leitura. Revista virtual de estudos da linguagem-ReVEL. Novo Hamburgo, RS. Vol. 16, nesp 15 (nov. 2018), p. 63-82, 2018.

DIMBARRE, J. B; HURKO, R.S; GLAP, L. A realidade dos alunos surdos inclusos nos anos iniciais. Trabalhos de Conclusão de Curso-Faculdade Sant'ana, 2017.

LIMA, A. V. L; CARNEIRO, A. P. L. A importância da sala de atendimento educacional especializado. In: II Congresso Internacional de Educação Inclusiva. 2016.

MOURA, L. L. A educação de surdos em São Francisco do Conde.Trabalho de Conclusão de Curso.Instituto de Humanidades e Letras da Universidade da Integração Internacional da Lusofonia Afro-brasileira (UNILAB) 2017.

NASCIMENTO, C.C. A surdez adquirida, o bilinguismo e a aquisição da identidade surda: história de uma vida. Trabalho de Conclusão de Curso de Graduação em Pedagogia, Universidade Estadual da Paraíba, Centro de Educação, 2017.

NÓBREGA, J. D. et al. Identidade surda e intervenções em saúde na perspectiva de uma comunidade usuária de língua de sinais. Ciência \& Saúde Coletiva, v. 17, p. 671$679,2012$.

NUVOLARI, D.A.R. Poluição sonora na modernidade e a escola-uma abordagem consciente nos hábitos auditivos de jovens professores. 2015. 
PASSOS, Y; SANTOS, W; CAMPELO, W. Língua de sinais na escola: comunicação como forma de interação entre surdos e ouvintes por meio dalibras na escola Luiz Nunes de direito. Littera on line, v. 9, n. Esp., 2018.

PERLIN, G; STROBEL, K. Fundamentos da educação de surdos. Florianópolis: UFSC, 2006.

SILVA, E. D. Sequência didática para aquisição de português como segunda língua para estudantes surdos: uma proposta. Entrepalavras, Fortaleza, v. 6, p. 168-181, jan./jun. 2016.

TIENSOLI, L. O. et al. Triagem auditiva em hospital público de Belo Horizonte, Minas Gerais, Brasil: deficiência auditiva e seus fatores de risco em neonatos e lactentes. Cadernos de Saúde Pública, v. 23, p. 1431-1441, 2007.

\section{Credenciais dos autores}

RIBEIRO, Raylene de Oliveira. Graduada em Psicologia pela Faculdade São Francisco de Barreiras - FASB; Pós-Graduada em Psicologia Educacional pela Universidade Leonardo da Vinci - UNIASSELVI. E-mail: ray.leny@ hotmail.com

LOUSEIRO, Maria da Conceição da Cunha. Graduada em Licenciatura Plena em Pedagogia pela Universidade Estadual do Piauí - UESPI, Especialista em Educação do Campo. E-mail: ceissalouseiro@gmail.com

Endereço para correspondência: Raylene de Oliveira Ribeiro. E-mail: ray.leny@hotmail.com

Como citar este artigo (Formato ABNT): RIBEIRO, Raylene de Oliveira; LOUSEIRO, Maria da Conceição da Cunha. Surdez na perspectiva da educação inclusiva. Educação, Psicologia e Interfaces, v. 4, n. 1, p. 106-113, 2020. DOI: https://doi.org/10.37444/issn2594-5343.v4i1.203

Recebido: 10/10/2019.

Aceito: 15/12/2019. 